HortSCIENCE 26(2):126-129. 1991.

\title{
Selective Limb Pruning Intensity Influences Mature Pecan Tree and Nut Characteristics
}

\author{
Ray E. Worley \\ University of Georgia, Coastal Plain Experiment Station, Tifton, \\ GA 31793 \\ Additional index words. Carya illinoensis
}

Abstract. Pecan [Carya illinoensis (Wangenh.) C. Koch] tree height was gradually reduced by removing one, two, or three limbs per year at a height $<9 \mathrm{~m}$. Pruning improved tree vigor and color, increased trunk circumference, terminal shoot growth, nut size, and leaf $\mathrm{N}, \mathrm{P}$, and $\mathrm{Mg}$, but reduced leaf $\mathrm{K}$ and percentage of fancy grade kernels relative to unpruned trees. Yield was not influenced by selective limb pruning.

Pecan trees are rarely pruned after initial structural training; however, many orchard situations exist where pruning may be beneficial. Orchards in the 1920s and 1930s were planted $18 \times 18 \mathrm{~m}$, or closer. Trees spaced $9 \times 9 \mathrm{~m}$, or closer, now are used in highdensity plantings. Trees in each of these situations have become crowded and nonprod-

Received for publication 13 Apr. 1990. The cost of publishing this paper was defrayed in part by the payment of page charges. Under postal regulations, this paper therefore must be hereby marked advertisement solely to indicate this fact. uctive. In crowded orchards, low limbs are shaded and die, limiting the bearing canopy to the top limbs, which become higher and more difficult to spray as trees age. Crowded orchards are usually thinned by removal of whole trees. Selective limb pruning might improve sunlight distribution within the tree, thus eliminating shading and limb death. Tall trees require larger and more expensive sprayers and more energy than shorter trees for adequate coverage. If crowding could be prevented or delayed by pruning, then the economics of pecan production might be enhanced. 


\begin{tabular}{|c|c|c|c|c|c|c|c|c|c|c|c|c|c|c|c|}
\hline \multirow[b]{2}{*}{ Treatmenty } & \multicolumn{14}{|c|}{ Crop year ${ }^{z}$} & \multirow[b]{2}{*}{$\operatorname{Mean}^{x}$} \\
\hline & 1975 & 1976 & 1977 & 1978 & 1979 & 1980 & 1981 & 1982 & 1983 & 1984 & 1985 & 1986 & 1987 & 1988 & \\
\hline \multicolumn{16}{|c|}{ Yield (kg/tree) } \\
\hline $\mathrm{PO}$ & 124 a & $22 a b$ & $7 \mathrm{ab}$ & 92 a & $29 \mathrm{~b}$ & $47 \mathrm{~b}$ & $56 \mathrm{~b}$ & $50 \mathrm{~b}$ & $30 a$ & $100 \mathrm{~b}$ & $20 a$ & $48 a b$ & $58 \mathrm{ab}$ & $78 \mathrm{a}$ & $54 \mathrm{bc}$ \\
\hline P1 & $134 \mathrm{a}$ & $17 \mathrm{a}$ & $13 \mathrm{~b}$ & 99 a & $22 \mathrm{ab}$ & $48 \mathrm{~b}$ & $55 \mathrm{~b}$ & $40 \mathrm{ab}$ & $36 \mathrm{a}$ & $89 \mathrm{ab}$ & $23 \mathrm{a}$ & $67 \mathrm{~b}$ & $61 \mathrm{~b}$ & $80 a$ & $55 \mathrm{c}$ \\
\hline $\mathrm{P} 2$ & $123 \mathrm{a}$ & $26 a b$ & $4 \mathrm{a}$ & $84 \mathrm{a}$ & $20 a b$ & $37 \mathrm{a}$ & 42 a & $34 \mathrm{a}$ & $30 a$ & $84 a$ & $23 a$ & $40 a$ & $42 \mathrm{a}$ & $74 \mathrm{a}$ & $47 \mathrm{a}$ \\
\hline P3 & 113 a & $30 \mathrm{~b}$ & $9 \mathrm{ab}$ & $85 \mathrm{a}$ & $14 \mathrm{a}$ & $40 a b$ & $32 a$ & $39 \mathrm{ab}$ & 31 a & $89 a b$ & $24 \mathrm{a}$ & $64 b$ & $43 a$ & $83 a$ & $50 \mathrm{ab}$ \\
\hline
\end{tabular}

${ }^{2}$ Mean separation by $t$ test (PDIFF), $P=0.05$.

$\mathrm{P} 0=$ no pruning; $\mathrm{P} 1, \mathrm{P} 2, \mathrm{P} 3=$ removed 1,2 , or 3 leaders per year, respectively.

'Mean separation for the means over years was by Duncan's multiple range test with the pruning $\times$ years interaction as the error term because the pruning

$x$ year component was significant.

Table 2. Effect of pruning intensity on pecan tree growth, appearance, and cropping intensities after 14 years.'

\begin{tabular}{|c|c|c|c|c|c|c|}
\hline \multirow{2}{*}{$\begin{array}{l}\text { Pruning } \\
\text { treatment }\end{array}$} & \multirow{2}{*}{$\begin{array}{c}\text { Trunk } \\
\text { circumference } \\
1988(\mathrm{~cm})\end{array}$} & \multirow{2}{*}{$\begin{array}{c}\text { Trunk } \\
\text { circumference } \\
\text { increase } \\
(\mathrm{cm})^{\mathbf{x}}\end{array}$} & \multirow{2}{*}{$\begin{array}{c}\text { Mean } \\
\text { terminal } \\
\text { growth } \\
\left(\mathrm{cm}^{-} \text {year }^{-1}\right)\end{array}$} & \multicolumn{2}{|c|}{ Mean rating ${ }^{w}$} & \multirow{2}{*}{$\begin{array}{c}\text { Mean fruit/ } \\
\text { terminal }\end{array}$} \\
\hline & & & & Vigor & Color & \\
\hline$\overline{\mathrm{PO}}$ & $191 \mathrm{a}$ & $23 \mathrm{a}$ & $8.0 \mathrm{a}$ & $5.2 \mathrm{a}$ & $5.3 \mathrm{a}$ & $0.9 \mathrm{a}$ \\
\hline P1 & $198 \mathrm{~b}$ & $25 \mathrm{~b}$ & $9.0 \mathrm{~b}$ & $5.8 \mathrm{~b}$ & $5.8 \mathrm{~b}$ & $1.0 \mathrm{ab}$ \\
\hline P2 & $198 \mathrm{~b}$ & $24 a$ & $8.8 \mathrm{~b}$ & $5.8 \mathrm{~b}$ & $5.9 \mathrm{bc}$ & $0.9 \mathrm{a}$ \\
\hline P3 & 193 a & $25 \mathrm{~b}$ & $10.4 \mathrm{c}$ & $6.2 \mathrm{c}$ & $6.1 \mathrm{c}$ & $1.1 \mathrm{~b}$ \\
\hline
\end{tabular}

${ }^{2}$ Mean separation was by GLM ANOVA with $t$ tcst (PDIFF), $P=0.05$.

${ }^{y} \mathrm{P} 0=$ no pruning; $\mathrm{P} 1, \mathrm{P} 2, \mathrm{P} 3=$ removed 1,2 , or 3 leaders per year, respectively.

${ }^{\times}$Circumference growth is 1988 tree circumference - initial circumference.

whating system for vigor and color was an arbitrary scale of 1 to 9 with $1=$ low vigor and light green color and $9=$ high vigor and dark green color.

Pecan pruning studies have been of insufficient duration to reach conclusive results. Some studies (Crane, 1932, 1933; Hardy, 1947) reported increased nut size from pruning, but few reported yield increases from pruning old trees (Crane, 1932; Crane and Dodge, 1932; Crane et al., 1935; Hardy, 1947; Reid, 1923, 1924). Pruning increased growth of remaining limbs, which increased fruit set and reduced fruit drop (Crane, 1933; Crane and Dodge, 1935; Sparks, 1988). Hedging pecan tops and sides reduced yield of 'Farley' and 'Desirable', but selective limb pruning did not reduce yield of 'Desirable' (Worley, 1985).

Severe pruning (dehorning), in which large limbs are cut back to stubs, reduces production for several years and stimulates vigorous growth near the cut, often causing more shading than occurred before pruning (Reid, 1924). If pruning is to be successful on old pecan trees, then vigorous regrowth must be reduced. A sprout inhibitor (1\% NAA) around pruning cuts has prevented sprout growth of lemon (Phillips and Tucker, 1974) and pear and apple (Raese, 1975). Gradual tree height reduction, where only a few limbs are removed each year and no limb stubs are left, might also reduce excessive water sprout regrowth and reduce yield losses due to removal of bearing limbs. If pruning were initiated before tree crowding, then the yield losses due to insufficient sunlight might be prevented. "Once the desired tree height is reached, then a "mold-and-hold" pruning system might maintain a productive tree in the allotted space. The objective of this study was to determine 1) if selective limb pruning would be a satisfactory alternative to no pruning and 2) which of three pruning severities was best when used with and without a chemical sprout inhibitor on mature 'Stuart' pecan trees before they become crowded.

Mature (> 50-year-old) 'Stuart' trees spaced $21 \times 21 \mathrm{~m}$ apart at Tifton, Ga., were used. The limbs of one tree were not yet touching those of adjacent trees; therefore, they were not considered to be crowded at the beginning of the study. Pruning treatments were initiated in 1975 and continued annually through 1988. Treatments were an unpruned control $(\mathrm{P} 0)$ and three intensities of winter pruning: removal of one $(\mathrm{P} 1)$, two $(\mathrm{P} 2)$, or three $(\mathrm{P} 3)$ limbs per tree per year at the first junction of another limb below a height of 9 $\mathrm{m}$. The tallest or the most crowded limbs were the ones usually removed, and, early in the test, these limbs usually exceeded 30 $\mathrm{cm}$ in diameter. Maximum tree height at the beginning of the study was $\approx 18 \mathrm{~m}$. Early years of the study, therefore, required removal of large limbs. Later years of the study involved a mold-and-hold technique where only those limbs that grew above $9 \mathrm{~m}$ were removed, still using the number of cuts specified by the treatment. Other pruning was limited to the removal of broken limbs and low limbs that interfered with equipment operation. Cuts were made using a chain saw operated from a self-propelled hydraulic bucket. Pruning time per tree was $\approx 10$ to 15 min. Pruning cuts were made distal to the collar at the junction between limbs so that the wound size was minimal without leaving a stub. Pruning wounds for half of the trees of each treatment were painted with $1 \%$ NAA (Tree-Hold Sprout Inhibitor A-12, Amchem Products, Ambler, Pa.) in a 1 white waterbase interior latex paint :1 water $(\mathrm{v} / \mathrm{v}) \mathrm{mix}$ ture or asphalt base aerosol; the other half remained untreated. The paint covered the wound and extended $2.5 \mathrm{~cm}$ onto the adjacent bark.

Leaf elemental concentrations were deter- mined by collecting 50 middle leaflet pairs from middle leaves from terminals in the area of maximum limbspread ( $=6$ to $9 \mathrm{~m}$ high) of each tree. Sampling was between the 2nd week of July and the 1st week of August each year (Plank, 1988), Leaves were visually clean, had not been sprayed with mineral elements, and were not washed (Plank, 1988). Leaves were dried and ground to pass a 20-mesh sieve. Duplicate 1-g samples were analyzed for $\mathrm{N}$ by an AOAC macro-Kjeldahl procedure (Horwitz, 1980). Leaf P was determined colorometrically and the cations $\mathrm{K}$, $\mathrm{Ca}$, and $\mathrm{Mg}$ were determined by atomic absorption spectroscopy (Worley, 1990).

Current season's terminal shoot growth was measured and fruit density (fruit per terminal) counted in the same area of the tree canopy and at the same time that leaf samples were collected. Twenty-five adjacent terminal shoots were measured in each quadrant of the tree, and the number of fruit present on 100 terminals was counted. Tree trunk circumference was measured annually in the area of minimum circumference between the root flange and the first limb and circumference increase was calculated. Vigor and leaf color ratings $(1=$ poor vigor or light green canopy, $9=$ excellent vigor or dark green canopy) were made visually for each tree in fall. The amount of limb breakage was measured, but no differences due to pruning treatment were detected.

Nuts from each tree were harvested, weighed, and a 50 -nut $(=0.5-\mathrm{kg})$ sample was removed for quality analysis. The in-shell nut sample was weighed and graded into commercial size categories by $1.6-\mathrm{mm}$ increments of diameter. The sample was then cracked and edible kernels were graded into fancy, standard, and amber color grades; percentages (of in-shell nuts) of each grade, total percentage kernel, and weight per nut were calculated. Edible kernels with defects and dark kernels were placed in the amber grade, the brightest kernels were graded fancy.

Trees were sprayed uniformly to control insects and disease. Drip irrigation was provided beginning in 1981. Orchard floor management was a closely mowed native sod with a weed-free herbicide strip in the tree row.

The statistical design was a completely randomized plot with each pruning treatment replicated 10 times with single-tree plots. Mean separation was by the SAS GLM procedure with the PDIFF option ( $t$ test) (Helwig and Council, 1979). PDIFF uses the 
Table 3. Effect of selective limb pruning vs. no pruning on pecan leaf elemental concentration.

\begin{tabular}{lccccc}
\hline \hline & \multicolumn{5}{c}{ Dry wt $(\%)^{z}$} \\
\cline { 2 - 6 } Pruning & $\mathrm{N}$ & $\mathrm{P}$ & $\mathrm{K}$ & $\mathrm{Ca}$ & $\mathrm{Mg}$ \\
\hline No & $2.65 \mathrm{a}$ & $0.127 \mathrm{a}$ & $1.05 \mathrm{~b}$ & $1.49 \mathrm{a}$ & $0.43 \mathrm{a}$ \\
Yes $^{y}$ & $2.72 \mathrm{~b}$ & $0.131 \mathrm{~b}$ & $1.00 \mathrm{a}$ & $1.53 \mathrm{a}$ & $0.45 \mathrm{~b}$ \\
\hline
\end{tabular}

${ }^{2}$ Mean separation by $\mathrm{t}$ test (PDIFF), $P=0.05$.

${ }^{y}$ Combined data for three pruning treatments and two sprout inhibitor treatments over 14 years.

Table 4. Effect of pruning intensity on pecan nut size and kernel quality, 1975-1988.'

\begin{tabular}{|c|c|c|c|c|c|c|c|}
\hline \multirow{3}{*}{$\begin{array}{l}\text { Pruning } \\
\text { treatment }\end{array}$} & \multirow{3}{*}{$\begin{array}{l}\text { Nut wt } \\
\text { (g/nut) }\end{array}$} & \multicolumn{2}{|c|}{ Size $(\%)^{x}$} & \multirow{2}{*}{\multicolumn{3}{|c|}{ Kernel quality (\%) ${ }^{w}$}} & \multirow{3}{*}{$\begin{array}{c}\text { Total } \\
\text { kernel } \\
(\%)\end{array}$} \\
\hline & & \multirow{2}{*}{$\begin{aligned} & >21 \\
< & 22 \mathrm{~mm}\end{aligned}$} & \multirow[b]{2}{*}{$>25 \mathrm{~mm}$} & & & & \\
\hline & & & & Fancy & Standard & Amber & \\
\hline P0 & $7.3 \mathrm{a}$ & $18.2 \mathrm{c}$ & $12.4 \mathrm{a}$ & $9.3 \mathrm{~b}$ & 33.9 a & $4.2 \mathrm{a}$ & $47.4 \mathrm{a}$ \\
\hline P1 & $7.7 \mathrm{ab}$ & $12.7 \mathrm{~b}$ & $21.8 \mathrm{~b}$ & $7.5 \mathrm{a}$ & $34.5 \mathrm{a}$ & $4.9 \mathrm{ab}$ & $47.0 \mathrm{a}$ \\
\hline $\mathrm{P} 2$ & $7.8 \mathrm{bc}$ & $12.7 \mathrm{~b}$ & $24.8 \mathrm{bc}$ & $7.0 \mathrm{a}$ & $34.6 \mathrm{a}$ & $5.5 \mathrm{~b}$ & $47.1 \mathrm{a}$ \\
\hline P3 & $8.1 \mathrm{c}$ & 8.9 a & $28.6 \mathrm{c}$ & $6.7 \mathrm{a}$ & $34.9 \mathrm{a}$ & $5.7 \mathrm{~b}$ & $47.3 \mathrm{a}$ \\
\hline
\end{tabular}

${ }^{2}$ Mean separation by $\mathrm{t}$ test $(\mathrm{PDIFF}), P=0.05$.

${ }^{y} \mathrm{P} 0$ = no pruning; P1, P2, P3 = removed 1, 2, or 3 leaders per year, respectively.

${ }^{\mathrm{x}}$ Size grades are by $0.16 \mathrm{~cm}(1 / 16 \mathrm{inch})$. A $13 / 16$ size nut will not pass through a 2.1 -cm-diameter hole but will pass a 2.2 -cm-diameter hole.

"Fancy grade kernels are brightest; amber are darkest. Edible kernels with defects were placed in the amber grade.

overall error as the error term for testing mean differences; therefore, if the year $\times$ pruning interaction was significant, then It was used as the error term for testing pruning effects over years and mean separation was by Duncan's multiple range test. There was little indication that the data followed a continuous pattern; therefore, regression analysis was not used.

Yield. Yields varied greatly from year to year due to the alternate-bearing nature of pecan trees (Table 1). Some yield reduction was expected in the early years of the study from heavy pruning. In 1979 and 1981 P3 reduced yield below that of the control and in 1980, 1981, and 1982, P2 yielded less than unpruned trees. Yields were similar for P0 and P1 treatments. Mean yields were higher for P1 than for P2 or P3. P2 was the only treatment that was different from $\mathrm{P} 0$ for the mean yield.

Tree growth, appearance, and cropping density. Trunk circumference was affected very little by 'the pruning treatments. Trunk circumference at the end of 14 years was larger for $\mathrm{P} 1$ and $\mathrm{P} 2$ trees than for $\mathrm{P} 0$ or $\mathrm{P} 3$ trees; however, trunk circumference increase (1988 circumference minus initial circumference) was greater for P1 and P3 trees than for P0 or P2 trees (Table 2). Differences in circumference increase were $\leq 2 \mathrm{~cm}$ over the 14-year period.

Pruning increased terminal shoot growth and improved tree appearance. Terminal shoot growth was greater when trees were pruned each year than when trees were not pruned, with $\mathrm{P} 3$ having the highest growth rate (Table 2). Pruning improved vigor and color of the trees compared with the unpruned trees, with P3 having greater vigor than any other treatment. The intensity of greenness of the canopy and fruit set were greater for P3 than for P0 trees (Table 2).

Leaf elemental concentration. Pruning increased the leaf elemental concentration of all elements analyzed, except $\mathrm{K}$ and $\mathrm{Ca}$ (Table 3). Pruning caused a small decrease in leaf K. Differences in elemental concentra- tion were small and were all within the sufficiency range suggested for pecans (Plank, 1988).

Nut size and kernel quality. Pruning generally increased nut size over the unpruned control when measured as grams per nut and consistently when measured as percentage of nuts in each size category. Increasing the intensity of pruning tended to increase nut size (Table 4). Most of the nuts were in the size category $>21$ but $<22 \mathrm{~mm}$ or larger. Unpruned trees produced a higher percentage of nuts in the size category $>21$ but $<22$ $\mathrm{mm}$ (small) and a lower percentage in the category $>25 \mathrm{~mm}$ (large) than the pruned trees.

Pruning slightly lowered kernel grade. Unpruned trees produced a higher percentage of fancy grade kernels than the pruned trees and a lower percentage of amber grade kernels than P2 or P3 trees. There was no difference in total percentage kernel among pruning treatments.

Effect of sprout inhibitor. The 1\% NAA sprout inhibitor reduced the amount of sprouting around the pruning wound (data not presented). The sprout inhibitor had little effect on the other variables measured. Most of the sprouts were within $30 \mathrm{~cm}$ of the pruning wound and were shaded and died within I to 2 years for both treated and untreated trees and did not become the problem that was anticipated. For this reason, sprout index measurements were discontinued after 1979.

'Stuart' bears fruit at the end of long limbs with little production toward the tree interior. Cultivars such as 'Western Schley' or 'Oklahoma', which bear fruit toward the interior of the tree, would be more likely to respond to pruning with increased yields than 'Stuart'. 'Stuart' is the cultivar planted most in early Georgia plantings and thus is the cultivar having the most problems with overcrowding. Many growers are removing other cultivars and leaving 'Stuart'; therefore, pruning methods that would make 'Stuart' remain productive are desired. A previous study indicated that hedge pruning was disastrous but that selective limb pruning may have promise as a production practice (Worley, 1985).

The results from this study indicated that pruning of mature 'Stuart' trees has advantages and disadvantages. The general appearance of pruned trees was better than that of unpruned trees. Pruned trees appeared more vigorous, and the canopy was darker green on pruned than unpruned trees. Pruned trees usually had higher leaf elemental concentrations than unpruned trees, which indicates that elements that would have gone into pruned limbs may have been redistributed to remaining limbs. Increased terminal shoot and increased circumference growth of pruned trees indicate that carbohydrate reserves are also being redistributed to the remaining limbs and trunk. Pruned trees were shorter than unpruned trees, and obviously received better spray coverage. A disadvantage to pruning was that there was not a large increase in fruiting density on limbs remaining after pruning, although there was a trend in that direction.

A major advantage to pruning is the increase in nut size. Large nuts usually bring higher prices when sold. Kernel quality, as shown by percentage kernel, was not influenced by treatments. Most of the kernels were in the standard grade for all treatments. Although unpruned trees had a greater percentage of kernels grading fancy and a smaller percentage grading amber, this difference never exceeded three percentage points and thus would make little difference in price received. The increased vegetative state of pruned trees might have delayed maturity and thus reduced the color characteristics of the kernels compared with unpruned trees.

The early yield loss from removal of top limbs was not serious. Although there was some yield loss from the two heaviest pruning regimes during the middle years of the study, the last 4 years of the study indicate the mold-and-hold system could maintain yields as well as PO. A previous study showed a doubling of yield of 'Desirable' in the 7th year of selective limb pruning, but that study was discontinued before. a mold-and-hold regime could be maintained (Worley, 1985). Selective limb pruning in that study was similar to P3 in the 'Stuart' study. For 'Stuart', removal of one limb per year appears most practical, because there was never a significant yield loss from this treatment.

Under present marketing conditions, pruning likely would not be cost effective. There was no yield advantage to pruning; thus, a large premium would have to be paid for the larger size of nuts from pruned trees to offset the cost of pruning. Pruning might become cost effective when unpruned trees become more crowded and less productive with time.

\section{Literature Cited}

Crane, H.L. 1932. Two years' results of pruning bearing pecan trees. Proc. Ga.-Fla. Pecan Growers Assn. 26:44-51. 
Crane, H.L. 1933. Results of pecan pruning experiments. Proc. Ga.-Fla. Pecan Growers Assn. 27:11-16.

Crane, H.L. and F.N. Dodge. 1932. The pruning of pecan trees: methods and equipment to be used. Proc. Ga.-Fla. Pecan Growers Assn. 26:51-57.

Crane, H.L. and F.N. Dodge. 1935. Influence of pruning and application of ammonium sulfate on the growth, distillate bloom and set of nuts on pecan trees. Proc. Amer. Soc. Hort. Sci. 33:42-45.

Crane, H.L., M.B. Hardy, F.N. Dodge, and N.H Loomis. 1935. The effects of thinning and stand of trees and other orchard practices on the growth and yield of pecans. Proc. Southeastern Pecan
Growers Assn. 29:27-35.

Hardy, M.B. 1947. Progress report on attempts to control biennial bearing in pecans. Proc. Southeastern Pecan Growers Assn. 40:54-62.

Helwig, J.T, and K.A. Council (eds.). 1979. SAS user's guide. SAS Institute, Inc. Cary, N.C.

Horwitz, W. (ed.). 1980. Official methods of analysis of the Association of Agricultural Chemists. 13th ed. p. 15 section 2.058. Assn. Offic. Agr. Chemists. Washington, D.C.

Phillips, R.L., and D.P.H. Tucker. 1974. Chemical inhibition of sprouting of pruned lemon trees. HortScience 9:199-200.

Plank, C.O. 1988. Plant analysis handbook. Ga Coop. Ext. Ser. Univ. of Georgia (unnumbered).
Raese, T.J. 1975. Sprout control of apple and pear trees with NAA. HortScience 10:396-398.

Reid, C.A. 1923. Pruning the pecan tree. Proc. Ga.-Fla. Pecan Growers Assn. 17:12-18.

Reid, C.A. 1924. Further notes on pecan pruning. Proc. Ga.-Fla. Pecan Growers Assn. 18:44-49.

Sparks, D. 1988. Effect of shoot vigor on distillate flower production and abortion in 'Stuart' Pecan. HortScience 23:570-571.

Worley, R.E. 1985. Effects of hedging and selective limb pruning of Elliott, Desirable, and Farley pecan trees under three irrigation regimes. J. Amer. Soc. Hort. Sci. 110:12-16.

Worley, R.E. 1990. Pecan leaf scorch in response to various combinations of nitrogen and potassium fertilization. HortScience 25:422-423. 